$f_{1} \mathrm{I}, 500$ and a Krupp $9{ }^{1}$-inch B.L. gum of $14 \frac{1}{2}$ tons costing $£ 3,453$, the length of the former was 125.5 inches and that of the latter 157.6 inches. Great complaints were justly made of the unfairness of the comparative trial, because, while the English gun was strictly confined to service conditions, the German gun was repaired and altered so that every feature of the original combination was changed. After some months' delay Krupp raised the initial velocity of his gun from I, I I5.3 f,s. to I, 286 or I,4 I 4 f.s., according to whether a $336 \mathrm{lb}$. shot or a $275 \mathrm{lb}$. shell was used. Time has now decided this contest. Here we remark how ready Krupp's party were to notice defects and apply remedies. If the English party were debarred from effecting improvements at Tegel, they were free to improve at home. They had seen that it was possible to construct a $9^{\frac{1}{4}}$-inch B.L. gun, firing lead-coated projectiles, which could compete with an English 9-inch M.L. gun. But we do not hear of any further attempts having been made to render the 110-pounder (about 7 inch) B.L. Armstrong gun an efficient weapon.

Last spring we were informed by authority that the new B.L. gun then about to be constructed would be double the length of the old B.L. gun. And quite recently the Times intimates a doubt about some newly constructed guns having sufficient strength in front of the trunnions to resist the full charge for which they were constructed. Now some years ago we heard a good deal about the doings of a Committee on Explosives, which carricd on experiments for several years, and at last reported. What could be the use of such a committee if it did not furnish rules for properly proportioning the strength of guns, and for determining the proper length of bore required for the profitable consumption of charges of slow-burning powder? Although Rodman and the pressure gauges and chronoscopes appear to have failed to give reliable results, it would not be difficult to contrive experiments which would give the practical valuc of cvery inch in length of the bore, and at the same time show the effect of great length of bore upon the steadiness of the motion of the elongated projectile.

In October, 1883 , it was stated in the papers that some comparative trials had been made at Portsmouth before "my lords," between a Krupp and an English 6.inch B.L. gun, "greatly to the advantage of the former." $\Lambda$ Krupp gun fired a $64 \mathrm{lb}$. shot with a $14 \mathrm{lb}$. charge and the English gun a $100 \mathrm{lb}$. shot with a $34 \mathrm{lb}$. charge. That is, the charge of the Krupp gun was two-ninths, and that of the English gun three-ninths of the weight of its shot. This increased charge might be a positive disadvantage to the English gun if it was a short one. This is a case requiring the most careful and candid investigation. Any fine moming a thorough comparison of the performances of these two guns might be carried oul in a searching manner, if only known means of doing this were employed. In order to succecd in gun-making it is absolutely necessary for careful experiments to be carried out to clear up anomalies, such as we have mentioned.

This work is illustrated by seventy-eight most carefully executed plates of guns, carriages, large steam hummers, and cranes, furnaces, plans of works, \&c., and it concludes with estimates of the expenses of cquipping a gun foundry according to modern requircinents.

Ti. B.

\section{ON THE FORMATYON OF SNOW CRYSTALS} FROM FOG ON BEN NEVIS

$I^{N}$ $\mathrm{N}$ addition to the actual fall of snow, hail, \&c., there is on Ben Nevis a form of solid precipitation scarcely known on lower ground, but of almost daily occurrence here. In ordinary weather the top of the hill is enveloped in drifting fog, and when the temperature of the air and ground is below freezing this fog deposits small crystalline particles of ice on every surface that obstructs its passage.
These particles on a wall or large sloping surface, so well described in a recent letter in NATURE (vol. xxxi, p. 216), combine to form long feathery crystals; but on a post or similar small body they take a shape more like fir-cones, with the point to windward. Whether this deposition is from the vapour of the fog directly or from actual particles of frozen water carricd along in it is not very clear. The forms and arrangements of the crystals vary according to the form of the surface to which they adhere, but all belong to this feathery or cone type, the branches Iying at an angle of $30^{\circ}$ with the main axis pointing to windward. They are formed wherever the wind blows past an obstructing body. On a flat board they gather first and most abundantly near its edges, forming a most beautiful border around it ; while the centre, which I suppose the wind does not directly reach, rcmains clear. A round post, on the contrary, has an almost uniform crop of these crystals all over its windward half, and so accurately do they point to windward that it is possible to trace changes in the direction of the wind from the successive layers of crystals lying at different angles. The rate of growth varies with the density of the fog and the speed of the wind, but for the ordinary winds and fogs of this exposed position about half an inch per hour may be taken as a rough average. I have never seen it excecd two inches per hour. If there is a damp feeling in the air, if in fact it is mist that is passing rather than fog, the crystals are icy and hard; but when the temperature is well below freezing and the fog fecls comparatively dry, they are looser in texture, seem when first formed to be attached by a mere point to whatever they are on, and are pretty casily knocked off. There is practically no limit to their growth ; last winter during a long continuance of strong south-westerly winds and cold weather a post 4 inches square grew into a slab of snow some 5 feet broad and $I$ foot thick in less than a week, the crystalline mass then fell off by its own weight and a new set began to form.

The effect of this growth on all the instruments exposed to its action may be easily imagined. Nothing keeps its shape or colour. The louvres of the Stevenson's screen for the thermometers bccome serrated with rows of teeth which quickly coalesce into a solid mass completely stopping any circulation of air inside the box. The use of exposed radiation thermometers, black bulb in vacuo, \&c., is rendered wcll nigh impossible, as these delicate glass instruments would run serious risk of breakage in clearing them of the deposit, while their readings would have little value, being merely the record of the temperature inside a more or less opaque mass of snow. Very often the rain-gauge is coated with these crystals an inch thick on its windward side, while not a particle is to be seen inside. Ordinary anemometers of the type of Dr. Rubinson's cup instrument become useless; the cups are no longer hemispheres, but irregular hollow bodies bristling all over with pointed crystals, and the arms carrying them increase to many times their original thickness, thus offering much greater surface for the wind to act on. Under such circumstances the anemometer at the Observatory is usually left to its own devices, and grows into an itregular mass of snow scarcely showing any trace of its original outline, to be cleared again whern dry weather or a thaw gives it a chance of working. When the fog comes on while the ancmometer is still turning, the crys. tals form chiefly on the outside of the cups and around their edges, leaving the insides pretty clear. The arms carrying the cups get completely covercd, and on the diagonal stays supporting the arms the crystals show a beautiful "twined" structure pointing downwards and outwards on each side.

Occasionally the crystals are smokey-brown in colour instead of white. For eximple, those found on December 23 , 1884 , were distinctly brown, but on the 24 th these were overlaid by a pure white set. What causes this 
change of colour and whether it is connected with any special state of the weather I have not yet determined.

Note.-Since the above was written, I have made a rough attempt to measure definitely the rate of growth of these crystals. A cylindrical stoneware bottle $3^{\cdot 6}$ inches high and 2.25 inches diameter was stuck upside down on a post 40 inches high for three hours at a time, the crystals formed on it melted down and the volume of the water measured. Assuming that the cylinder acted like a flat surface placed perpendicularly to the wind whose height and breadth are equal to its height and diameter-an assumption that appears to be very nearly true, at least for small surfaces-I find that with dense fog and strong wind (force 6 to 8 of Beaufort's scale) the rate of growth, as measured above, is about $0^{\circ} 125$ inch per hour. That is to say, if the density of the snow be one-tenth that of the water, the crystals were growing at the rate of one and a quarter inch per hour. The crystals were quite loose and feathery, and contained practically no fallen or drifted snow; all had been formed directly out of the fog.

R. T. OMOND

\section{BIRD ARCHITECTURE}

$\mathrm{T}$

$\mathrm{HE}$ way in which a bird builds its nest, seemingly without instruction, thought, or experience, has been repeatedly brought forward as a convincing proof of blind infallible instinct governing it in its task. No more popular proof has been brought forward by the supporters of the blind instinct theory than that of bird-architecture. It is thought a wonderful thing for a bird to build a nest without any instruction, or without ever seeing a nest typical of its species. That birds are capable of such marvellous powers has long ago been denied by $\mathrm{Mr}$. Wallace, and we have not a particle of evidence that such is really the case ("Nat. Selection," and Seebohm's "Brit. B.," ii. Introd.). Indeed the evidence, such as we can glean, goes far to disprove the presence of any such instinctive power. Birds brought up in confinement have been found not to make a nest typical of their species, but generally content themselves with forming a rudimentary structure-heaping a lot of material together without any design, or even laying their eggs on the bare ground with no provision at all! In my opinion, however, the conditions of life are so changed when a bird is kept in confinement that too much weight should not be attached to its actions in captivity, and the experiment has never to my knowledge fairly been tried with wild birds or birds living under normal conditions.

A remarkable instance, however, of a changed mode of nest-building has just been brought to my notice by Mr. W. Burton, the well-known naturalist of Wardour Street. Some time ago his brother: (now employed at the museum at Wellington, N.Z.) took out to New Zealand a number of young birds of our common native species, with the object of introducing them to the Antipodes. Amongst them were some young chaffinches (Fringilla calebs). These were turned out and have thriven well in a wild state, bidding fair to permanently establish this charming little bird in our distant colonies. Some of the birds have built a nest; and to Mr. Burton I am indebted for a photograph of the wonderful structure they have woven. It is evidently built in the fork of a branch, and shows very little of that neatness of fabrication for which this bird is noted in England. The materials with which it is made seem very different, too. The cup of the nest is small, loosely put together, apparently lined with feathers, and the walls of the structure are prolonged for about eighteen inches, and hang loosely down the side of the supporting branch. The whole structure bears some resemblance to the nests of the Hangnests (Icteridæ), with the exception that the cavity containing the eggs is situated on the top. Clearly these New Zealand chaffinches were at a loss for a design when fabricating their nest.
They had no standard to work by, no nests of their own kind to copy, no older birds to give them any instruction, and the result is the abnormal structure I have just described. Perhaps these chaffinchesimitated in some degree the nest of some New Zealand species; or it may be that the few resemblances this extraordinary structure presents to the typical nest of the Palæarctic chaffinch are the results of memory - the dim remembrance of the nest in which they had been reared, but which had almost been effaced by novel surroundings and changed conditions of life. Any way we have here, at last, a most interesting and convincing proof that birds do not make their nests by blind instinct, but by imitating the nest in which they were reared, aided largely by rudimentary reason and by memory. I have not the least doubt that, had these young chaffinches been hatched in an alien nest in this country, and never allowed to see a nest typical of their species, or have any connection with old and experienced birds, the results would have been still more startling and strange. Man has to learn the particular art of house-building practised by his own peculiar race -birds have to do the same! CHARLES DIXON

\section{THE INSTITUTION OF NAVAL ARCHITECTS}

THE Annual Meetings of the Institution of Naval Architects were held during the week preceding Easter at the rooms of the Society of Arts. There were five sittings, at which the necessary routine business was transacted, the presidential address of Lord Ravensworth was delivered, and seventeen papers were read and discussed. On the whole the meetings were successful and the papers of good quality, but far too much work was attempted in the time available. It is to be hoped that the growing importance of the proceedings and the improving financial position of the Institution may lead the Executive to arrange for holding regular autumnal sessions at the principal outports, in addition to the spring sessions in London.

The papers read were chiefly "papers of information," having a strictly practical or descriptive character, only two or three having scientific pretensions. Marine engineering also occupied a far more prominent place than has been usual hitherto, nearly one-half of the papers having relation to the propelling apparatus of steamships. The fact is significant, indicating the remarkable progress which has recently been made in marine engineering, and suggesting the progress which may yet be made. Of the papers coming into this group, that by Mr. Macfarlane Gray, of the Board of Trade, was the only one of a scientific nature. Mr. Gray has on more than one occasion brought his "ether-pressure" theory before the Physical Society, where it has not been well received. His recent paper "On the Theoretical Duty of Heat in the SteamEngine" was probably understood by only a few of his hearers; and Prof. Cotterill, whose authority on the subject is undoubted, was the only speaker who really contributed any useful criticism. While complimenting Mr. Gray on some of his graphic processes, and expressing admiration for his courage and perseverance, Prof. Cotterill took exception to the generalisations attempted in the paper and to the assumption that the results so far obtained were any real confirmation of the soundness of the theory advanced.

All the other engincering papers were of a practical character. The actual performances of "triple-expansion" engines as compared with the "double-expansion" or ordinary compound marine engines, were discussed at length. Experience appcars to be conclusive on the point that, by using steam of 120 to 150 pounds' pressure, and having three successive expansions in separate cylinders, an economy of from 15 to 20 per cent. in coal consumption is to be realised. This economy is of the highest importance, both in mercantile and war ships 